Review

\title{
Sustainable Food Production: The Contribution of Genome Editing in Livestock
}

\author{
Alejo Menchaca ${ }^{1,2}$ (D) \\ 1 Fundacion IRAUy, Instituto de Reproducción Animal Uruguay, 12200 Montevideo, Uruguay; \\ menchaca.alejo@gmail.com \\ 2 Institut Pasteur Montevideo, Unidad Mixta Pasteur INIA, 11400 Montevideo, Uruguay
}

check for

updates

Citation: Menchaca, A. Sustainable Food Production: The Contribution of Genome Editing in Livestock. Sustainability 2021, 13, 6788. https:// doi.org/10.3390/su13126788

Academic Editor: Gerhart U. Ryffel

Received: 16 March 2021

Accepted: 1 June 2021

Published: 16 June 2021

Publisher's Note: MDPI stays neutral with regard to jurisdictional claims in published maps and institutional affiliations.

Copyright: (C) 2021 by the author. Licensee MDPI, Basel, Switzerland. This article is an open access article distributed under the terms and conditions of the Creative Commons Attribution (CC BY) license (https:// creativecommons.org/licenses/by/ $4.0 /)$.

\begin{abstract}
The growing demand for animal source foods to feed people has been pushing the livestock industry to increase productivity, a tendency that will continue throughout this century. The challenge for the coming years is to increase the food supply to ensure equity in access to high quality food, while maintaining global sustainability including combating climate change, avoiding deforestation, and conserving biodiversity, as well as ensuring animal health and welfare. The question is, how do we produce more with less? Classical methods to enhance livestock productivity based on the improvement of animal health, nutrition, genetics, reproductive technologies and management have made important contributions; however, this is not going to be enough and thus disruptive approaches are required. Genome editing with CRISPR may be a powerful contributor to global livestock transformation. This article is focused on the scope and perspectives for the application of this technology, which includes improving production traits, enhancing animal welfare through adaptation and resilience, conferring resistance to infectious diseases, and suppressing pests and invasive species that threaten livestock. The main advantages and concerns that should be overcome by science, policy and people are discussed with the aim that this technology can make a real contribution to our collective future. This review is part of the special issue "Genome Editing in Animal Systems to Support Sustainable Farming and Pest Control".
\end{abstract}

Keywords: CRISPR; gene editing; transgenesis; gene drive; precision breeding; One Health

\section{Introduction}

One of the greatest challenges of this century is how to face the increasing demand for food required by a growing world population. Throughout history, population expansion, environmental/climate change, and resource overexploitation have pressed humans to find better strategies to get food or, eventually, change their dietary habits. The current growth in world food consumption is not only driven by population growth, which will be almost 10 billion people by 2050 [1], but also by the greater per capita consumption of animal protein over vegetable carbohydrates (i.e., better quality food) as a result of greater disposable household income [2]. Over the last 30 years, extreme poverty has fallen from $35 \%$ to $9 \%$, and consumption of meat, milk, and eggs in low- and middle-income countries has more than tripled. According to FAO projections, food demand in these countries will increase by more than 200 percent by 2050 [3]. With advances in production, human beings could achieve access to good quality food for almost the entire global population for the first time in history. No poverty and zero hunger, two of the Sustainable Development Goals pursued by United Nations [4], may be 'economically feasible' during this century. However, some questions remain. Are we prepared to produce more food? Could the planet bear it?

\section{Livestock and Sustainability}

The extensive livestock production systems have largely relied on increasing the land area used for feeding animals to increase production. From a global prospective, this 
strategy is no longer feasible because we are reaching the limits of usable space on the planet [5]. It is not only an economic matter or an environmental concern, but in some regions it is also a physical limitation. During the past century, intensification by increasing the yield of livestock produced on the same land surface allowed an increase in productivity by improving efficiency $[6,7]$, with the modern dairy industry being the most prominent example requiring considerably fewer resources per product unit than dairying in the middle of the last century. However, intensive farming practices based on maximizing productivity and profitability without consideration for environmental conservation have led to negative consequences. Focusing solely on increasing production is not compatible with natural resource conservation, and leads us to endless discussions such as intensive vs. organic production systems, or natural vs. synthetic foods, neither of which allows meeting both global production requirements and environmental conservation. To address this dilemma in the global context, livestock transformation is required, and new technologies are necessary (Figure 1). 


\section{Global trends}

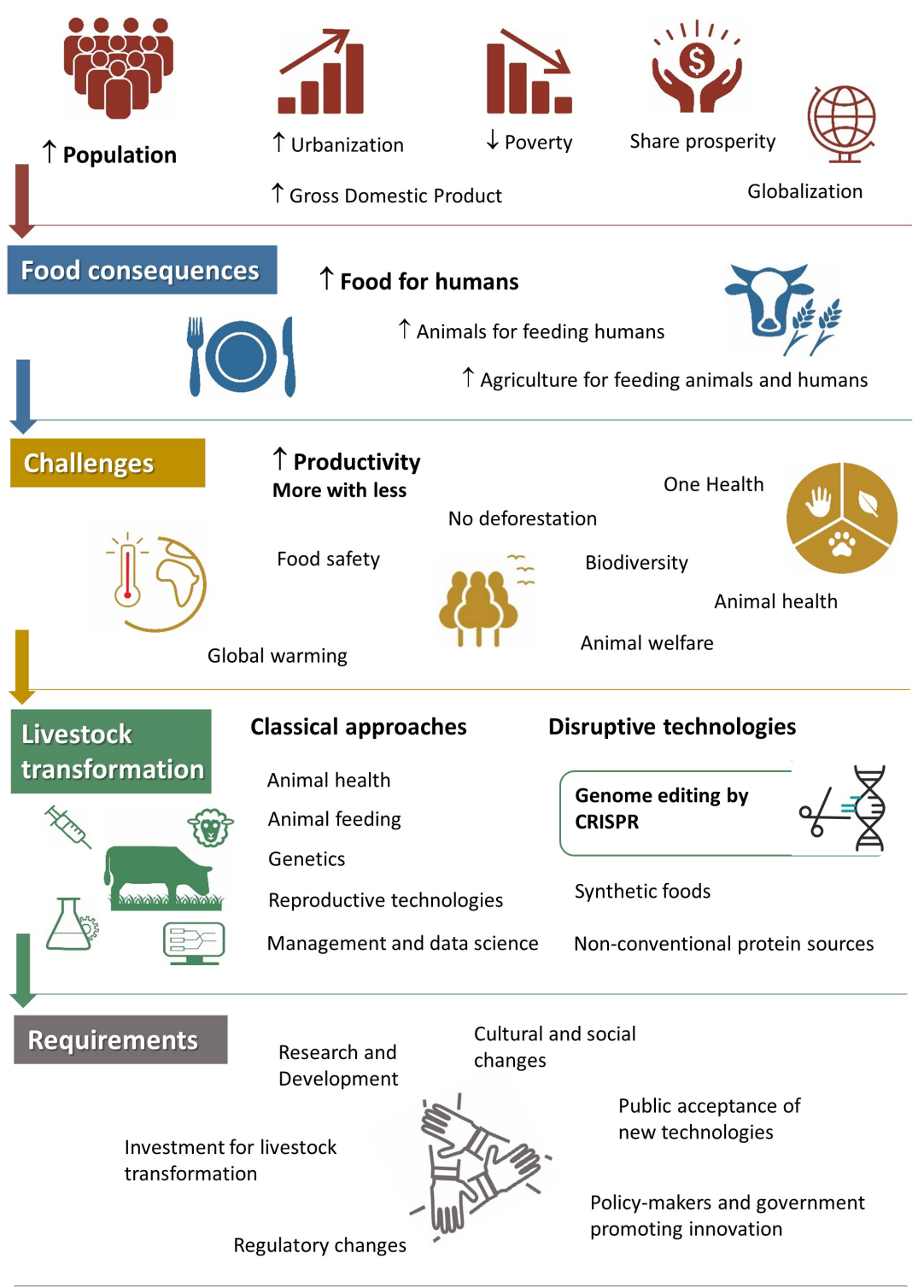

Figure 1. Global trends driving food production and livestock transformation. Global trends in the twenty-first century are dominated by human population growth, which is being associated with improving gross domestic product, decreased poverty, and shared prosperity, as well as increasing urbanization and globalization. The main consequence for the food supply is the need to increase animal production for feeding humans, and agriculture for feeding both animals and humans. The challenge is how to increase productivity while conserving the environment and biodiversity, ensuring animal welfare and health, and guaranteeing food safety and human health. A livestock transformation will be able to accomplish these goals, first by improving classical approaches related to animal health, feeding, genetic improvement, reproductive technologies, and management assisted by data science and artificial intelligence; and second, by developing potentially disruptive technologies like genome editing with CRISPR, or exploring alternative strategies like synthetic food and other non-conventional protein sources. The requirements for livestock transformation are not only research and development (R\&D) and investment from the private sector, but also cultural changes. Governments and policymakers will need to develop appropriate regulatory systems to allow these novel tools to be assessed, and opinion leaders and media will play a role in public acquaintance with these new technologies. 


\section{The Arrival of Genome Editing}

The CRISPR/Cas system, and previously TALEN and ZFN, are relatively recent genome editing tools that will contribute to the global livestock transformation. Applications of genome editing include improving productive and fitness traits in large animals, enhancing animals to achieve adaptation and resilience to ensure animal welfare, generating resistance to infectious and transmissible diseases, as well as controlling pests and disease vectors. Previous reviews have described the technical basis of this technology in livestock, and many scientific articles provide information on possible drawbacks and technical refinements to improve efficiency (e.g., see $[8,9])$. This review is focused on the scope and future perspectives for the application of this technology.

Since the first report of CRISPR-edited mammals was published in 2013 using mice [10], the CRISPR/Cas system has revolutionized genome engineering for a number of species. The technology was rapidly adapted to pigs [11,12], goats [13], sheep [14], and later to cattle [15]. The main use to date is CRISPR's ability to edit the genome acting as molecular scissors with the ability to edit any given sequence including a single nucleotide. In the past century, the transfer of genetic material in a controlled and deliberate manner between animals was based on transgenesis, a novel approach where a transgene injected into an early-stage embryo would be integrated into the host genome. The so-called transgenic animals were first produced by pronuclear zygote microinjection of foreign DNA [16], a random phenomenon that often resulted in unexpected, variable and inefficient transgene expression patterns [17]. In the years that followed, homologous recombination in embryonic stem cells provided a suitable solution for gene targeting in mice and rats; nevertheless, this system never worked in livestock species [18,19]. With Dolly the sheep, the somatic cell nuclear transfer (SCNT) approach made it possible to alter endogenous loci directly in other species, opening an opportunity in livestock species [19]; but difficulties in nuclear reprogramming and low efficiency in obtaining viable offspring, requiring laborious and lengthy protocols, made this technology available only to a handful of research groups. In general, the implementation of genome engineering technologies was extremely difficult for small laboratories, with many projects being technically infeasible. In addition, any genome modification mediated by transgenesis never gained the sympathy of the general public, which discouraged research and investment. The need for a simpler, inexpensive, more efficient, and transgenesis-free technology to target modification of animal genomes was therefore necessary. With the arrival of genome editing and the CRISPR/Cas system, these issues were overcome and the technology is now ready to use.

\section{How Genome Editing Improves Livestock}

Genome editing applications in livestock have been reported in proof-of-concept studies, research projects, as well as proposed for commercial use as seen by the increase in market-oriented studies. Since 2014, when the first reports with CRISPR/Cas system in large animals were published, the number of scientific reports published in peer reviewed journals increased to approximately 200 reports per year in 2020 (Scopus searching using CRISPR and cattle, or cows, or sheep, or goats, or pigs). Some leading genetic companies with a global presence, operating in different species, have announced innovative projects to apply genome editing-based technology to design specific traits in domestic animals. Recent developments indicate that this tool could be available in the market of genomeedited farm animals in the near future. An overview of the contribution of this technology to livestock transformation is depicted in Figure 2, and some examples of genome-edited animals illustrating the main or first reported ideas are summarized below. 


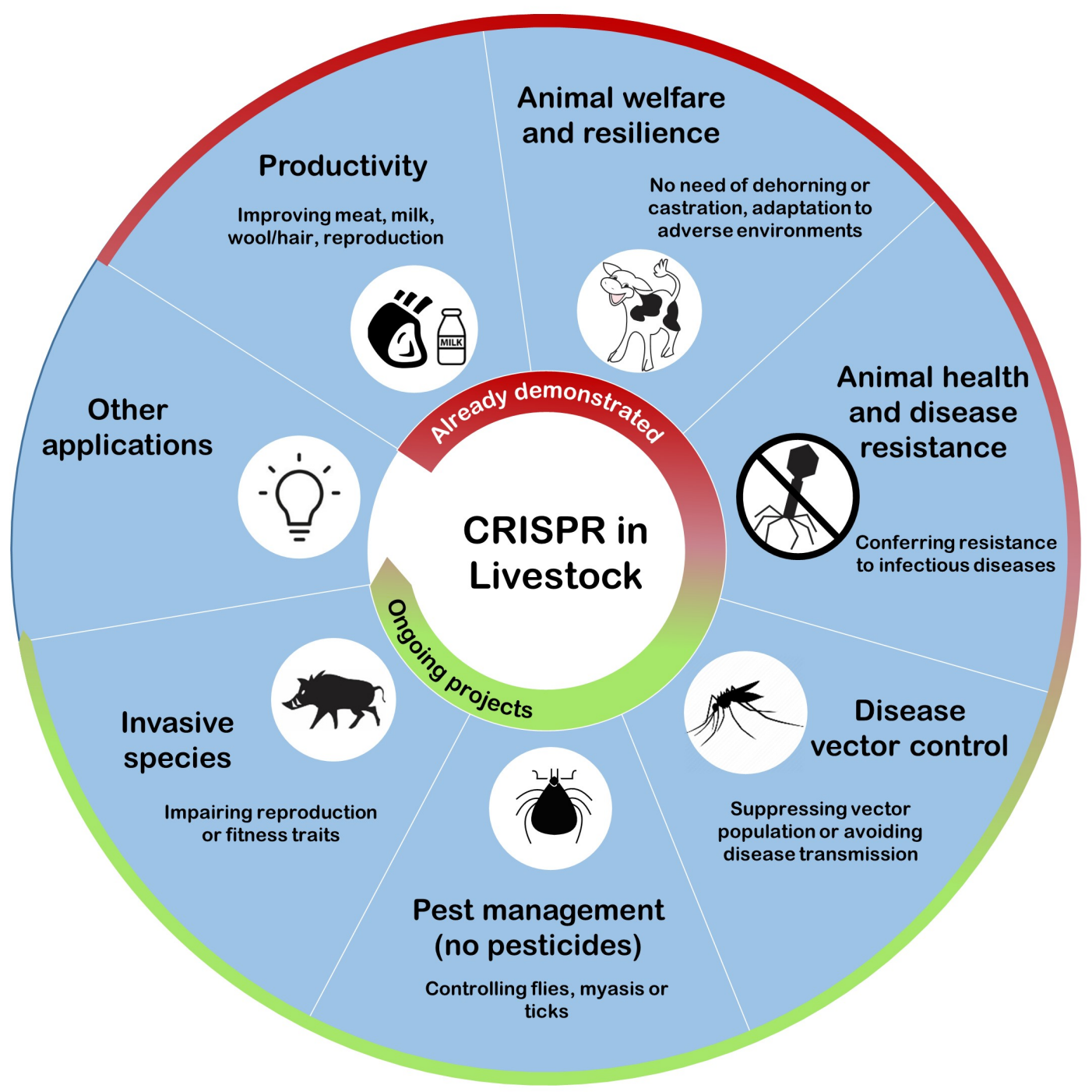

Figure 2. The contribution of CRISPR to livestock. Genome editing using the CRISPR/Cas system may improve livestock according to different strategies: (1) Improving animal productivity in terms of food quantity and quality; (2) Enhancing animal welfare by avoiding unnecessary invasive practices or conferring resilience to adverse environments; (3) Suppressing disease vector populations or impairing their ability to transmit disease; (4) Controlling pests like flies, ticks, and other species harming livestock; (5) Decreasing invasive species affecting livestock by impairing their propagation. Some of these applications have already been demonstrated, while others are currently being developed, and new ideas may be explored since the plasticity of genome editing technology has not yet been exhausted.

\subsection{Yield and Quality Related Traits}

Multipurpose breeds that efficiently express more than one desirable trait (such as cows that produce milk and meat) are a rare achievement in animal husbandry. For centuries, farmers have used classical approaches like breeding and selection to breed cows to produce milk and meat, or sheep to produce both meat and wool. However, multipurpose breeds are often at a disadvantage compared to specialized breeds, and many farmers have ended up accepting that the best decision is to obtain specialized animals for a single trait (e.g., meat, milk, wool, hair). This paradigm in livestock may be changed with CRISPR. Sheep with greater growth performance and high quality wool using CRISPR was one of the first models demonstrated in livestock [14]. Superfine Merino is recognized as the best breed of sheep to produce the finest and highest quality wool, but this breed has a lower growth rate and smaller sized lambs compared with other breeds. On the other hand, several sheep breeds have been improved over the years by classical genetics (i.e., selective 
breeding) to produce meat, at the cost of low-quality wool. A good example is Texel, the most popular breed in the Netherlands and distributed worldwide. The impressive growth rate and meat production of these lambs is associated with a spontaneous mutation at the MSTN gene encoding for myostatin (or GDF8) that is involved in muscle cell growth and differentiation. Suppressing MSTN produces sheep with more muscle mass relative to sheep without the mutation. In our study [14], Superfine Merino zygotes were used as a genetic background to introduce an MSTN mutation by CRISPR/Cas9 microinjection. As a result, double muscle lambs were obtained, thus achieving a greater growth rate that led to a $25 \%$ heavier body weight than Superfine Merino lamb counterparts, while maintaining the same wool quality traits as Merino lambs [8]. Similar outcomes were also reported in Cashmere goats to produce high quality hair and double muscle phenotype [20]. Methods to produce these dual-proposal animals achieved in Uruguay and China are further compared for both sheep and goats [21], making this technology available to laboratories worldwide. Amazingly, these early studies suggested that what farmers have pursued for centuries might be achieved with CRISPR in only a few months.

Genome editing may also be useful for improving food components and consumer health. For example, beta-lactoglobulin, encoded by the BLG gene, is the main component from ruminant milk that can cause an allergic reaction in some adults. Current approaches to reducing the allergenicity of milk require significant costs because fermentation often increases its immuno-reactivity. An alternative approach could be the generation of productive breeds, knocking-out the gene encoding this protein. Researchers in China employed the CRISPR/Cas9 system to produce BLG-knockout goats, successfully abolishing the presence of $\beta$-lactoglobulin in milk [22]. In New Zealand, a similar approach to disrupting BLG using TALEN was reported in cows [23]. These edited animals that produce $\beta$-lactoglobulin-free milk provide a valuable approach for the safe production of hypoallergenic cows' milk, which could supply millions of people who suffer from an allergy to this basic food with access to it.

CRISPR may also be applied to improve animal husbandry by altering the sex ratio. Male:female ratio is particularly relevant when the desired product is provided by only one sex (e.g., meat from males or milk from females) or when the reproductive rate of a given species is intended to be suppressed. A male-only offspring strategy has been proposed for beef cattle [24], since males grow faster and are bigger than females, improving efficiency and avoiding the necessity of female culling by farmers. Another approach has been proposed in pigs to suppress testis development in the fetal gonadal ridges resulting in a female phenotype and avoiding the undesirable male-specific boar taint [25]. Both strategies still need to be proven and require further investigation. Of particular interest for science, but requiring significant progress before its application in industry, is the possibility of generating germ cells from high-merit donor animals and introducing them to the gonads of otherwise sterile host animals, thereby expanding the availability of gametes from genetically desirable dams and sires. Sterile ovaries from NANOS3 knockout cows [26] and sterile testes from NANOS2 knockout male pigs and goats [27,28], were able to harbor or express exogenous stem cells from donor animals for regeneration of wild-type gametes. The application of this research could provide an alternative to avoid bottlenecks in genetic improvement programs, facilitating the spread of superior genetics through natural service in surrogate animals of adapted breeds, or increasing the spread of top sires by artificial insemination that are often unable to produce sufficient doses of semen to address demand.

These examples show the potential of genome editing to improve livestock by editing single genes responsible for specific production traits. Other traits are known to be influenced by many quantitative trait nucleotides most of them with a small effect, which require a multiplexed editing strategy that is more complex but also possible to explore [29]. In both cases, with monogenic or polygenic traits, genome editing allows increasing or decreasing the frequency of those alleles affecting particular traits, and, when incorporated 
into breeding programs and associated with reproductive technologies like in vitro embryo production and artificial insemination, can make a significant contribution to genetic gain.

\subsection{Animal Welfare}

Consumers around the world are increasingly concerned with the wellbeing of the animals they eat. Innovations that promote animal welfare play a critical role in improving sustainable livestock production. Traditional approaches for improving animal welfare in livestock include adapting management and environment to avoid the suffering of animals. But what about adapting animals to avoid painful practices and suffering? The concept of welfare-enhanced animals is a novel strategy proposed to avoid animal suffering, designing animal genetic adaptation and resilience. Many routine procedures used to mitigate some of the consequences of intensive livestock production, such as dehorning in calves, male castration, tail-docking in dairy cattle, mulesing in sheep, or abortion or culling of an undesired gender, often results in immediate or chronic pain. Some of these practices may become unnecessary with the use of genome editing.

Horn removal, usually using a hot-iron or chemical burning to destroy the hornproducing cells of the horn bud, is a routine practice in dairy calves to avoid horn growth in adults and prevent them from harming other animals or workers. However, during this procedure, calf pain and stress is an inevitable consequence increasingly questioned by consumers. Several beef breeds like Angus, are naturally horn-free due to a dominant trait referred to as polled, with two allelic variants on the bovine chromosome 1. Classical genetics strategies like selective breeding to introduce this polled trait from beef cattle into dairy cattle have been ineffective mainly due to the loss of productive traits acquired during decades of selection. Carlson et al. [30] introgressed the causative Celtic mutation (Pc) into the Holstein cattle genome resulting in a polled phenotype of the offspring. Using TALEN, they demonstrated how genome editing may be useful to reduce physical dehorning in dairy cattle without loss of productivity, and without suffering. When crossing one of these polled bulls with horned cows, the calves had no horns and were otherwise healthy and phenotypically unremarkable, and no other unintended genomic alterations were found [31]. Semex, a Canadian-based farmer-owned cattle genetics organization with a global presence, has participated in the development of this strategy with the aim of applying this technology in the dairy cattle industry [32].

Male castration is a routine practice for several livestock species. In pigs, it is mainly conducted to eliminate boar taint, an unpleasant odor and unsavory taste. Generating an only-female phenotype has been proposed in pigs, which would offer new opportunities to end surgical castration in this species $[25,27]$. Castration-free piglets produced by genome editing has been announced by Hendrix Genetics [33], a European multi-species genetics company with a global presence, representing an important step towards ending one of the biggest concerns of the pig industry regarding animal well-being.

Animals are exposed to conditions in nature that can be stressful or hazardous. Resilience of domestic animals for adaptation to adverse environments may be improved by copying and pasting specific genetic sequences from naturally adapted or evolved local breeds to intensively selected breeds. As an example, heat stress is a serious limitation for high productivity Holstein cattle that has an impact on animal comfort, welfare, health, reproduction, feed intake and production. Some spontaneous mutations in genes linked to heat stress adaption can improve animal ability to regulate body temperature in certain hot environmental conditions [34]. One example of this is the slick mutation of PRLN, conferring a better adaptation to hot climate. This mutation can be found in Caribbean criollo-derived cattle and has been adapted into Holstein dairy cattle through classical genetics tools, improving adaptation to heat stress without apparently decreasing milk production [34]. Recombinetics, a privately held biotechnology company located in the US, has led the application of this technology in farm animals, the company announced the successful birth of genome edited Angus calves produced by introgression of Slick mutation in Brazil [35]. It seems that this technology has fallen in the right place and at 
the right time. Brazil is one of the largest beef meat exporters in the world, with livestock raised in hot climates, and having an interesting regulation system for genome editing.

This technology offers novel opportunities to improve animal welfare, which may encourage public embrace of genome-edited animals to be used in the food supply chain. In addition, through these strategies it is possible to expand livestock towards adverse environments, or increase productivity in current conditions, and thus improve the world's food supply.

\subsection{Animal Health}

A pandemic affecting livestock is a permanent threat that can have a devastating impact on food supply and the economy, including production, industry, and trade of live animals and derived products. Even worse, animal infectious diseases may be transmitted to humans and produce serious impact, like COVID-19 which caused the death of about 3 million people in little more than one year [36]. Because about 70\% of human diseases have come from animals, in a context of an increasing global animal population to produce more food, animal health requires more effort and more innovative solutions than in the past. According to OIE [37], intensification of livestock production, among other factors, predisposes to an unprecedented increase in emerging and re-emerging animal diseases and zoonosis. Livestock expansion is mainly supported in high-density animal monocultures, which represent a particular threat for the spread of infectious diseases from farm animals to humans. Where domestic animals are a conduit from wild animals to humans, high density livestock production may facilitate the spread of zoonotic diseases [38]. At the same time, in a context of a more intensive production system, farmers will need to combat diseases facing increased antimicrobial resistance and pressure from consumers to minimize the use of antibiotics, which ultimately also affects public health. In this regard, the relevance of new efforts such as the One Heath initiative to attain optimal health for people, animals and the environment, is recognized more and more worldwide. For those countries trying to supply food in this century, livestock practices should not be considered if not aligned with those approaches in accordance with the One Health initiative.

In this sense, genome editing can contribute to the generation of disease-resistant animals. The generation of pigs resistant to porcine respiratory and reproductive syndrome virus (PRRSV) has been achieved by two different laboratories in the US [39] and in the UK [40], which serves as a good example. Economic losses in the pork industry due to PRRSV account for more than 2.5 billion dollars per year in the US and Europe. Methods to control the disease have not yet been developed, and depopulation, sterilization, and repopulation seem to be the only ways to control an outbreak of this virus. By targeting the virus receptor CD163 using CRISPR, PRRSV resistant pigs can be generated. Reported CD163 edited piglets have been demonstrated to be completely resistant to North American and European PRRSV strains $[39,40])$, showing no symptoms and suffering no infection following an in vivo viral challenge. This achievement has received financial support from and collaboration with Genus plc [41], an international leader in the porcine and bovine genetics industry that announced in 2019 that it was seeking FDA approval for this application.

Pig meat is a major source of protein in human diets, with a stable share of $35-40 \%$ of global meat consumption [42]. What would happen if a worldwide pandemic affected this meat source? Far from speculation, this has occurred recently. The epidemic of African swine fever (ASF) has produced massive losses in the pork industry in Asia and Eastern Europe, and puts other regions at risk. According to the OIE [42], this epidemic first surfaced in China in 2018 and then spread to over 50 countries including those that account for $75 \%$ of global pork production. In addition to the approximately 200 million animals that suffered from the disease and died, this epidemic has disturbed the meat and crop market with great global consequences [43]. This gap from the pork industry had a noticeable worldwide effect on both meat and animal feed markets, while bovine, poultry and ovine meat demand increased, maize and soybean use in pig feed declined. 
African swine fever is a transboundary animal disease caused by the ASF virus that affects all breeds and ages of pigs, for which there are no approved vaccines and euthanasia is required, with up to $100 \%$ case fatality rate. Although the virus affects domestic and wild pigs, the infection is generally asymptomatic in warthogs (Phacochoerus africanus, a kind of wild pig of sub-Saharan Africa), with no clinical signs of disease. This type of resistance to ASF virus in the warthog was associated with a variation in the RELA gene, which encodes a major component of the NF- $\mathrm{KB}$ transcription factor that plays a key role in regulating the immune response to infections [44]. Researchers from The Roslin Institute in UK have proposed that this warthog sequence could be engineered into the domestic pig genome to reduce disease after ASF virus infection. In a first approach, the authors achieved the genome editing of the domestic pig RELA locus and generated live born animals with the warthog RELA orthologue. Although promising progress was published in different reports [45-47], in a recent study it was found that the substitution of warthog NF- $\mathrm{B}$ motifs into RELA of domestic pigs was not sufficient to confer resilience to ASF virus [48]. However, a delay in onset of clinical signs and less viral DNA in blood samples and nasal secretions was observed in some animals. The authors suggest that inclusion of these and additional warthog genetic traits into domestic pigs may be one way to combat the devastating impact of ASF disease.

Genome editing has also been used to generate pigs resistant to classical swine fever (CSF) virus, one of the other major detrimental diseases that leads to significant economic losses in the pork industry. By using a CRISPR/Cas9-mediated knock-in strategy, antiviral small hairpin RNAs were inserted at the porcine Rosa26 locus to produce CSF virus resistant pigs by somatic cell nuclear transfer [49]. Viral challenge confirmed that the edited pigs could effectively limit the replication of CSF virus, and the disease resistance traits in the founders were stably transmitted to the offspring. While $100 \%$ of the wild type pigs died after a viral challenge with clear symptoms of CSFV disease, all the genome edited pigs remained alive during the experimental period. Other examples of using CRISPR for animal health improvement include producing coronavirus resistant pigs, by editing a putative receptor of the transmissible gastroenteritis virus [50], and editing cows to increase their resistance to tuberculosis, which were produced through the CRISPR/Cas system in China [15].

Overall, CRISPR appears as a novel strategy to control infectious diseases in livestock by editing single genes involved in the host sensitivity to the pathogen. This application provides unprecedented opportunities for the control of classical and new infectious diseases with high impact in animal and public health, international trade, and the global economy.

\subsection{Pest and Disease Vector Control}

Pest species and disease vectors generate significant losses in animal production and the global food supply, since approximately $45 \%$ of annual food production is lost due to pest infestation. The increased use of chemicals to manage this problem could compromise the environment, with approximately 4 million tons of pesticides sprayed onto the global landscape each year [51]. Compounding the problem is that many of the most important arthropod pest species have developed resistance to a majority of the currently available pesticides used for their control.

CRISPR-based strategies hold the potential to control pests and disease vectors without the use of chemicals or pesticides. The question is how do you spread these traits induced by the CRISPR/Cas system in a non-controlled wild population? For that, the genome editing system described above has been adapted to create a "driving mechanism", named gene drive, to increase the chances of the edited trait being passed on to the offspring [52,53]. Usually, according to Mendelian inheritance, one copy of a gene has a $50 \%$ chance of being included in any gamete, but with gene drives it can be present in a higher fraction (up to $100 \%$ ) of gametes and offspring. This occurs because the system contains genetic elements able to bias their own inheritance to be present in the gametes. As a consequence, gene drives can rapidly spread into a given population, with the potential that after releasing 
relatively few individuals containing the gene drive, the entire population can incorporate it within several generations. Gene drive refers to a phenomenon that occurs naturally in some organisms that use sexual reproduction and can also be induced in the laboratory, mainly with the CRISPR/Cas system. The CRISPR/Cas system makes this mechanism of gene drive technically feasible and controllable, and is now available for use in wild species in order to introduce or suppress a given trait into the extant population via mating. After identifying and modifying genetic determinants of key traits such as reproduction fitness, male:female ratio, or certain characteristics required to remain viable in nature, the species is suppressed and finally tends to disappear.

How could CRISPR-based gene drive systems be used to support other efforts behind global sustainability? This technology may be applied via two different approaches: (i) spread a gene drive that negatively affects the ability of adults to reproduce, thereby debilitating the population as it spreads; or (ii) spread a gene drive containing an engineered genetic construct that modifies the vector's ability to harbor a given pathogen. The first approach is useful to control pest and invasive species, and the second approach is also useful to control different kinds of vector borne diseases. One of the major difficulties for genetic control of a wild population is to spread and maintain a given trait over time, since unlike domestic species, breeding and reproduction is not controlled. For this reason, success of spreading a given edited DNA fragment into insects or invasive species is completely different than in domestic animals. Whereas in domestic animals a given male carrying the desired trait may be genetically exploited under our desired control by using intensive breeding and reproductive technologies (i.e., artificial insemination and embryo transfer), in wild species any trait carried by few males introduced into the population may be rapidly neutralized and disappear due to the natural mechanisms of Mendelian inheritance. To avoid effect exerted in wild populations, the plasticity of CRISPR/Cas technology (in this case applied to induce gene drive system) appears as a novel and promising strategy for biological control.

Various pests, invasive species, and disease vectors are currently being studied as potential applications for control by this strategy $[54,55]$. Application of this tool transcends livestock production, and includes potential benefits for the environment, as well as animal and public health. An example of how this technology may be applied to control a vector borne disease is the case of controlling mosquitos to eradicate malaria. This project is one of the most advanced gene drive initiatives and is being used as reference for forthcoming projects in other species. The control of malaria has been a global public health priority for almost 100 years [56]. Each year, more than 400,000 people die from this disease, most of them children under the age of five, while more than 3 billion people remain at risk for infection [57]. The situation is more pronounced in sub-Saharan Africa, where the deadliest malaria parasite, Plasmodium falciparum, coexists with the most efficient malaria vector, the Anopheles mosquito. In these countries, the control of malaria would not only reduce human suffering and mortality, but also would provide significant socio-economic benefit through increased productivity and quality of life for populations living in malariaendemic regions [58]. The use of the CRISPR/Cas machinery is envisioned to make more practical and realizable large-scale campaigns to drastically decrease malaria incidence. Pioneering studies demonstrated that this technology has the potential to achieve mosquito population suppression [59-61] or to alter its capacity to transmit pathogens causing the disease $[53,62,63]$.

Vector-borne diseases have broad relevance for both human health and livestock production, since the same vector-pathogen system often affects human and animal health, and in some cases multiple host species can play epidemiologically significant roles. A full one-quarter of the terrestrial vertebrate pathogens of concern to the OIE are vector borne [64]. In addition to the example of malaria, CRISPR-based strategies may confer different traits to other vector species to control diseases in animals and humans, such as dengue, Zika virus, chikungunya, yellow fever, trypanosomiasis, leishmaniasis, Chagas, and Lyme disease, among others. Various species of mosquitoes, flies and ticks gener- 
ate significant losses in food production as vectors of different diseases or directly by their action on the host species. Some of these species have been proposed or are under study to be addressed by CRISPR-based strategies. In our case, a collaborative project between researchers from Uruguay and the US is ongoing to apply this technology to Cochlyomia hominivorax, a fly that produces screwworm myasis in warm blooded species causing suffering and death in affected animals, and economic losses in South American countries of about 3.6 billion dollars each year [65]. Although most of the information related to CRISPR-based gene drive has been reported in insects, this technology also can be developed for mammals [66].

\subsection{Invasive Species}

After insects, vertebrate invasive species are likely to be the next target for CRISPRbased strategies in wild populations. Invasive species are often introduced into new environments where they become established and cause harm to human health, agriculture, and the environment. Environmental degradation, threatening of local biodiversity, extinction of native wildlife species, and agricultural or livestock losses are consequences often incurred in different regions after invasive species have been introduced. The Global Invasive Species Database published by the International Union for Conservation of Nature [67] recognizes thousands of invasive species, with some species of rats, rabbits, squirrels, wild boars, possums, foxes, and cane toads among the top 100 of the world's worst invasive alien species whose population should be controlled. While important efforts to manage invasive species are ongoing (e.g., shooting, poisoning, trapping, or killing with other predators), current methods are usually primitive, costly, have varying levels of efficacy at low population densities, are often associated with unacceptable suffering for target and non-target species, may have unintended ecological consequences, and are usually limited to short-term results in population control [55].

Gene drives are now being discussed as tools to reduce invasive animal populations or to aid threatened species, since it may offer a more cost-effective, humane, and species-specific alternative to current approaches [52]. CRISPR-based strategies previously described for suppression of invertebrate pest populations by skewing the sex ratio or affecting fertility in favor of males, may also be applied to vertebrate invasive species. A grossly male population will result in a population decline, while an all-male population will lead to suppression. However, although successful in mosquitos, technical challenges exist for the adaption of this technology into vertebrates. Different CRISPR-based strategies may be applied to achieve this mechanism in vertebrates, and the technical bases have been addressed in previous reports [68-71]. Briefly, two main strategies are proposed [68]. Targeting female fertility: the release of heterozygous animals carrying a gene drive system expressing Cas9 and guide RNAs encoded to disrupt a haplosufficient female-fertility gene in the first generation. This cassette will cut this gene out of the wild-type chromosome of the germ cells. The DNA is then repaired through the homology-direct repair (HDR) system, with the gene drive chromosome as the repair template, with most sperm or eggs carrying the gene drive system. After successive mating, homozygosity of the gene will lead to female offspring infertility [68,71]. The second, X-Shredder, uses the gene drive system expressing Cas9 and sgRNAs, which are located on the Y-chromosome. During spermatogenesis, it will shred the $\mathrm{X}$-chromosome beyond repair. The majority of offspring will thus be male with the ability to transmit the X-shredder chromosome to the offspring using the same gene drive system $[69,70]$. These methods present technical challenges for vertebrate adaptation, and are actively being studied in various laboratories around the world.

\section{Limitations Beyond Science}

Facing the global challenges discussed above, CRISPR-based strategies make livestock transformation possible. Through this technology, it is possible to shape nature as never before, in a very precise manner, in a few generations, at a relatively low cost, and with 
minimal infrastructure compared to any other strategy. However, although it is technically feasible and the benefits seem to be clear, genome editing and particularly gene drive still need to be further evaluated, accepted by the public, and approved for use in nature. If we consider the developments in genome editing to be technically amazing and biologically unbelievable, finding a consensus among people to apply this technology will be even more challenging.

The scope in society that this kind of technology can achieve beyond the research bench depends on the amount of interest generated by farmers and industry, consumer and public acceptance, and appropriate regulatory frameworks. Taking into account the advantages that this technology will provide to the private sector and general public discussed in this article, the application seems to be a matter of time. However, the regulatory framework to apply this tool in livestock deserves particular consideration.

Approval of genome-engineered organisms requires safety consideration specific to the species in which it will be applied, to non-target species including humans, and the environment. The first technology involving molecular intervention in the genome was transgenesis, which led to a real revolution in agriculture, pharmaceuticals and biotechnology. This tool was not incorporated into livestock due in part to regulatory requirements that were excessive compared to the same technology applied in other industries (i.e., plants, microorganisms, and cells). With the arrival of the CRISPR/Cas-based technology, transgenesis is becoming obsolete. In contrast to transgenesis, the CRISPR/Cas system does not require exogenous DNA to be introduced randomly into the host genome (genome editing is not transgenesis). For this reason, and because application of genome editing in many countries is not regulated in plants and other organisms, its use in the animal industry should be more easily approved. However, a consensus among regulatory agencies does not exist and a lack of harmonization has led to important differences among countries.

Some countries apply a reasonable criterion that if there is no 'new combination of genetic material' and the final product is free of 'transgenes', then that product will not be subject to the same regulation as a genetically modified organism (GMO). The US applies this principle for genome editing in plants, however, in the same country the criterion is the complete opposite in animals. In the US, edited animals are subjected to regulations established for transgenic animals, which means they are treated under the drug regulatory system, which in essence is closing the research and future application of this technology [72]. In the EU, genome editing both in plants and animals is treated as transgenic under the regulation of GMOs, which represent a current constraint to the use of this technology. The European scientific community signed an Open Statement in 2019 [73] claiming that it "urgently calls upon the European institutions including the European Council, the new European Parliament and the upcoming European Commission to take appropriate legal action to enable European scientists and breeders to apply genome editing for sustainable agriculture and food. The ability to use genome editing is crucial for the well-fare and food security of European citizens." More than 130 European research institutes and associations supported this document. On the other hand, many countries in South America (led by Argentina and Brazil), East Asia (led by Japan), the Middle East (e.g., Israel), and Oceania (e.g., Australia) have more appropriate systems based on the type of event to be evaluated to define which kind of regulation is applied. In these systems, the properties of the resulting product are assessed on a case-by-case basis. China has not defined a specific regulatory status for genome editing products but has the highest number of research publications and patents for agricultural applications of CRISPR [74,75]. These countries are called to lead this transformation based on more appropriated technologies than conventional strategies.

\section{Conclusions}

We face the challenge of how to adequately supply food for a growing human population while integrating animals, people, and the environment into a global health approach. From this perspective, our actions can be divided into those that are part of the problem and 
those that are part of the solution. In a context in which a unique technology is unlikely to solve a global matter, CRISPR-based strategies have appeared as a novel tool to contribute to a livestock transformation. This paper outlines some of the different approaches to be applied with this technology to improve food production, animal welfare and resilience, animal health, and to control vector borne diseases, pests, and invasive species. These new strategies are empowering the private sector and the public to be part of the solution. Governments also have a role to play by updating their regulatory systems in a pragmatic way to ensure the use of safe technologies without unnecessarily hampering progress.

Funding: This research received no external funding.

Institutional Review Board Statement: Not applicable.

Informed Consent Statement: Not applicable.

Data Availability Statement: Data sharing is not applicable to this article.

Conflicts of Interest: The author declares no conflict of interest.

\section{References}

1. United Nations. World Population Prospects: The 2017 Revision; United Nations: New York, NY, USA, 2017.

2. World Bank. Poverty and Shared Prosperity 2020: Reversals of Fortune; World Bank: Washington, DC, USA, 2020.

3. FAO. Shaping the Future of Livestock Sustainably, Responsibly, Efficiently; FAO: Berlin, Germany, 2018.

4. ICSU; ISSC. Review of the Sustainable Development Goals: The Science Perspective; International Council for Science (ICSU): Paris, France, 2015.

5. Ritchie, H.; Roser, M. Land Use-Our World in Data. Available online: https://ourworldindata.org/land-use (accessed on 15 February 2021).

6. Capper, J.L.; Cady, R.A.; Bauman, D.E. The Environmental Impact of Dairy Production: 1944 Compared with 2007. J. Anim. Sci. 2009, 87, 2160-2167. [CrossRef]

7. White, R.R.; Brady, M.; Capper, J.L.; McNamara, J.P.; Johnson, K.A. Cow-Calf Reproductive, Genetic, and Nutritional Management to Improve the Sustainability of Whole Beef Production Systems. J. Anim. Sci. 2015, 93, 3197-3211. [CrossRef]

8. Menchaca, A.; dos Santos-Neto, P.C.; Mulet, A.P.; Crispo, M. CRISPR in Livestock: From Editing to Printing. Theriogenology 2020, 150, 247-254. [CrossRef]

9. Hennig, S.L.; Owen, J.R.; Lin, J.C.; Young, A.E.; Ross, P.J.; Van Eenennaam, A.L.; Murray, J.D. Evaluation of Mutation Rates, Mosaicism and off Target Mutations When Injecting Cas9 MRNA or Protein for Genome Editing of Bovine Embryos. Sci. Rep. 2020, 10, 22309. [CrossRef] [PubMed]

10. Wang, H.; Yang, H.; Shivalila, C.S.; Dawlaty, M.M.; Cheng, A.W.; Zhang, F.; Jaenisch, R. One-Step Generation of Mice Carrying Mutations in Multiple Genes by CRISPR/Cas-Mediated Genome Engineering. Cell 2013, 153, 910-918. [CrossRef]

11. Hai, T.; Teng, F.; Guo, R.; Li, W.; Zhou, Q. One-Step Generation of Knockout Pigs by Zygote Injection of CRISPR/Cas System. Cell Res. 2014, 24, 372-375. [CrossRef]

12. Whitworth, K.M.; Lee, K.; Benne, J.A.; Beaton, B.P.; Spate, L.D.; Murphy, S.L.; Samuel, M.S.; Mao, J.; O'Gorman, C.; Walters, E.M.; et al. Use of the CRISPR/Cas9 System to Produce Genetically Engineered Pigs from In Vitro-Derived Oocytes and Embryos1. Biol. Reprod. 2014, 91, 78-79. [CrossRef]

13. Ni, W.; Qiao, J.; Hu, S.; Zhao, X.; Regouski, M.; Yang, M.; Polejaeva, I.A.; Chen, C. Efficient Gene Knockout in Goats Using CRISPR/Cas9 System. PLoS ONE 2014, 9. [CrossRef] [PubMed]

14. Crispo, M.; Mulet, A.P.; Tesson, L.; Barrera, N.; Cuadro, F.; Dos Santos-Neto, P.C.; Nguyen, T.H.; Crénéguy, A.; Brusselle, L.; Anegón, I.; et al. Efficient Generation of Myostatin Knock-out Sheep Using CRISPR/Cas9 Technology and Microinjection into Zygotes. PLoS ONE 2015, 10. [CrossRef]

15. Gao, Y.; Wu, H.; Wang, Y.; Liu, X.; Chen, L.; Li, Q.; Cui, C.; Liu, X.; Zhang, J.; Zhang, Y. Single Cas9 Nickase Induced Generation of NRAMP1 Knockin Cattle with Reduced Off-Target Effects. Genome Biol. 2017, 18, 13. [CrossRef]

16. Hammer, R.E.; Pursel, V.G.; Rexroad, C.E.; Wall, R.J.; Bolt, D.J.; Ebert, K.M.; Palmiter, R.D.; Brinster, R.L. Production of Transgenic Rabbits, Sheep and Pigs by Microinjection. Nature 1985, 315, 680-683. [CrossRef]

17. Menchaca, A.; Anegon, I.; Whitelaw, C.B.A.; Baldassarre, H.; Crispo, M. New Insights and Current Tools for Genetically Engineered (GE) Sheep and Goats. Theriogenology 2016, 86, 160-169. [CrossRef]

18. Capecchi, M. Altering the Genome by Homologous Recombination. Science 1989, 244, 1288-1292. [CrossRef]

19. Tan, W.; Proudfoot, C.; Lillico, S.G.; Whitelaw, C.B.A. Gene Targeting, Genome Editing: From Dolly to Editors. Transgenic Res. 2016, 25, 273-287. [CrossRef]

20. Wang, X.; Yu, H.; Lei, A.; Zhou, J.; Zeng, W.; Zhu, H.; Dong, Z.; Niu, Y.; Shi, B.; Cai, B.; et al. Generation of Gene-Modified Goats Targeting MSTN and FGF5 via Zygote Injection of CRISPR/Cas9 System. Sci. Rep. 2015, 5, 13878. [CrossRef] 
21. Kalds, P.; Crispo, M.; Li, C.; Tesson, L.; Anegon, I.; Chen, Y.; Wang, X.; Menchaca, A. Generation of Double-Muscled Sheep and Goats by CRISPR/Cas9-Mediated Knockout of the Myostatin Gene. Methods Mol. Biol. 2021, in press.

22. Zhou, W.; Wan, Y.; Guo, R.; Deng, M.; Deng, K.; Wang, Z.; Zhang, Y.; Wang, F. Generation of Beta-Lactoglobulin Knock-out Goats Using CRISPR/Cas9. PLoS ONE 2017, 12, e0186056. [CrossRef]

23. Wei, J.; Wagner, S.; Maclean, P.; Brophy, B.; Cole, S.; Smolenski, G.; Carlson, D.F.; Fahrenkrug, S.C.; Wells, D.N.; Laible, G. Cattle with a Precise, Zygote-Mediated Deletion Safely Eliminate the Major Milk Allergen Beta-Lactoglobulin. Sci. Rep. 2018, 8, 7661. [CrossRef]

24. Owen, J.R.; Hennig, S.L.; McNabb, B.R.; Mansour, T.A.; Smith, J.M.; Lin, J.C.; Young, A.E.; Trott, J.F.; Murray, J.D.; Delany, M.E.; et al. One-Step Generation of a Targeted Knock-in Calf Using the CRISPR-Cas9 System in Bovine Zygotes. BMC Genom. 2021, 22. [CrossRef]

25. Kurtz, S.; Petersen, B. Pre-Determination of Sex in Pigs by Application of CRISPR/Cas System for Genome Editing. Theriogenology 2019, 137, 67-74. [CrossRef]

26. Ideta, A.; Yamashita, S.; Seki-Soma, M.; Yamaguchi, R.; Chiba, S.; Komaki, H.; Ito, T.; Konishi, M.; Aoyagi, Y.; Sendai, Y. Generation of Exogenous Germ Cells in the Ovaries of Sterile NANOS3-Null Beef Cattle. Sci. Rep. 2016, 6, 24983. [CrossRef]

27. Park, K.E.; Kaucher, A.V.; Powell, A.; Waqas, M.S.; Sandmaier, S.E.S.; Oatley, M.J.; Park, C.H.; Tibary, A.; Donovan, D.M.; Blomberg, L.A.; et al. Generation of Germline Ablated Male Pigs by CRISPR/Cas9 Editing of the NANOS2 Gene. Sci. Rep. 2017, 7, 40176. [CrossRef]

28. Ciccarelli, M.; Giassetti, M.I.; Miao, D.; Oatley, M.J.; Robbins, C.; Lopez-Biladeau, B.; Waqas, M.S.; Tibary, A.; Whitelaw, B.; Lillico, S.; et al. Donor-Derived Spermatogenesis Following Stem Cell Transplantation in Sterile NANOS2 Knockout Males. Proc. Natl. Acad. Sci. USA 2020, 117, 24195-24204. [CrossRef]

29. Jenko, J.; Gorjanc, G.; Cleveland, M.A.; Varshney, R.K.; Whitelaw, C.B.A.; Woolliams, J.A.; Hickey, J.M. Potential of Promotion of Alleles by Genome Editing to Improve Quantitative Traits in Livestock Breeding Programs. Genet. Sel. Evol. 2015, 47, 55. [CrossRef]

30. Carlson, D.F.; Lancto, C.A.; Zang, B.; Kim, E.S.; Walton, M.; Oldeschulte, D.; Seabury, C.; Sonstegard, T.S.; Fahrenkrug, S.C. Production of Hornless Dairy Cattle from Genome-Edited Cell Lines. Nat. Biotechnol. 2016, 34, 479-481. [CrossRef]

31. Young, A.E.; Mansour, T.A.; McNabb, B.R.; Owen, J.R.; Trott, J.F.; Brown, C.T.; Van Eenennaam, A.L. Genomic and Phenotypic Analyses of Six Offspring of a Genome-Edited Hornless Bull. Nat. Biotechnol. 2020, 38, 225-232. [CrossRef]

32. Semex. Recombinetics and Semex Form Alliance to Improve Animal Well-Being. Available online: https://www.semex.com/us/ i?lang=en\&news=list\&id=1527559162 (accessed on 15 March 2021).

33. The Alliance to End Surgical Castration of Swine Announces Precision Breeding Successes-Hendrix Genetics Corporate. Available online: https:/ / www.hendrix-genetics.com/en/news/alliance-end-surgical-castration-swine-announces-precision-breedingsuccesses / (accessed on 15 March 2021).

34. Hansen, P.J. Prospects for Gene Introgression or Gene Editing as a Strategy for Reduction of the Impact of Heat Stress on Production and Reproduction in Cattle. Theriogenology 2020, 154, 190-202. [CrossRef]

35. This Gene-Edited Calf Could Transform Brazil's Beef Industry / Moving Upstream-YouTube. Available online: https://www. youtube.com/watch?v=lvDYGSAMiWk (accessed on 15 March 2021).

36. WHO Coronavirus (COVID-19) Dashboard I WHO Coronavirus Disease (COVID-19) Dashboard. Available online: https: / / covid19.who.int/ (accessed on 15 March 2021).

37. Slingenbergh, J.; Gilbert, M.; De Balogh, K.; Wint, W. Ecological Sources of Zoonotic Diseases. OIE Rev. Sci. Tech. 2004, 23, 467-484. [CrossRef]

38. King, K.C.; Lively, C.M. Does Genetic Diversity Limit Disease Spread in Natural Host Populations. Heredity (Edinb) 2012, 109, 199-203. [CrossRef]

39. Whitworth, K.M.; Rowland, R.R.R.; Ewen, C.L.; Trible, B.R.; Kerrigan, M.A.; Cino-Ozuna, A.G.; Samuel, M.S.; Lightner, J.E.; McLaren, D.G.; Mileham, A.J.; et al. Gene-Edited Pigs Are Protected from Porcine Reproductive and Respiratory Syndrome Virus. Nat. Biotechnol. 2016, 34, 20-22. [CrossRef]

40. Burkard, C.; Opriessnig, T.; Mileham, A.J.; Stadejek, T.; Ait-Ali, T.; Lillico, S.G.; Whitelaw, C.B.A.; Archibald, A.L. Pigs Lacking the Scavenger Receptor Cysteine-Rich Domain 5 of CD163 Are Resistant to Porcine Reproductive and Respiratory Syndrome Virus 1 Infection. J. Virol. 2018, 92. [CrossRef]

41. The Future of Animal Health Is Here-Progressive Dairy. Available online: https://www.progressivedairy.com/topics/a-ibreeding/the-future-of-animal-health-is-here (accessed on 15 March 2021).

42. Perspective Opinions and Strategies. Panorama 2020. Available online: https://oiebulletin.com/wp-content/uploads/2020 /Panorama2020-1/panorama-2020-1-en.pdf (accessed on 15 March 2021).

43. Mason-D'Croz, D.; Bogard, J.R.; Herrero, M.; Robinson, S.; Sulser, T.B.; Wiebe, K.; Willenbockel, D.; Godfray, H.C.J. Modelling the Global Economic Consequences of a Major African Swine Fever Outbreak in China. Nat. Food 2020, 1, 221-228. [CrossRef]

44. Palgrave, C.J.; Gilmour, L.; Lowden, C.S.; Lillico, S.G.; Mellencamp, M.A.; Whitelaw, C.B.A. Species-Specific Variation in RELA Underlies Differences in NF-B Activity: A Potential Role in African Swine Fever Pathogenesis. J. Virol. 2011, 85, 6008-6014. [CrossRef]

45. Lillico, S.G.; Proudfoot, C.; Carlson, D.F.; Stverakova, D.; Neil, C.; Blain, C.; King, T.J.; Ritchie, W.A.; Tan, W.; Mileham, A.J.; et al. Live Pigs Produced from Genome Edited Zygotes. Sci. Rep. 2013, 3, 2847. [CrossRef] 
46. Lillico, S.G.; Proudfoot, C.; King, T.J.; Tan, W.; Zhang, L.; Mardjuki, R.; Paschon, D.E.; Rebar, E.J.; Urnov, F.D.; Mileham, A.J.; et al. Mammalian Interspecies Substitution of Immune Modulatory Alleles by Genome Editing. Sci. Rep. 2016, 6. [CrossRef]

47. Tait-Burkard, C.; Doeschl-Wilson, A.; McGrew, M.J.; Archibald, A.L.; Sang, H.M.; Houston, R.D.; Whitelaw, C.B.; Watson, M. Livestock 2.0-Genome Editing for Fitter, Healthier, and More Productive Farmed Animals. Genome Biol. 2018, 19, 204. [CrossRef]

48. McCleary, S.; Strong, R.; McCarthy, R.R.; Edwards, J.C.; Howes, E.L.; Stevens, L.M.; Sánchez-Cordón, P.J.; Núñez, A.; Watson, S.; Mileham, A.J.; et al. Substitution of Warthog NF-KB Motifs into RELA of Domestic Pigs Is Not Sufficient to Confer Resilience to African Swine Fever Virus. Sci. Rep. 2020, 10, 2045-2322. [CrossRef] [PubMed]

49. Xie, Z.; Pang, D.; Yuan, H.; Jiao, H.; Lu, C.; Wang, K.; Yang, Q.; Li, M.; Chen, X.X.; Yu, T.; et al. Genetically Modified Pigs Are Protected from Classical Swine Fever Virus. PLoS Pathog. 2018, 14, e1007193. [CrossRef]

50. Whitworth, K.M.; Rowland, R.R.R.; Petrovan, V.; Sheahan, M.; Cino-Ozuna, A.G.; Fang, Y.; Hesse, R.; Mileham, A.; Samuel, M.S.; Wells, K.D.; et al. Resistance to Coronavirus Infection in Amino Peptidase N-Deficient Pigs. Transgenic Res. 2019, $28,21-32$. [CrossRef] [PubMed]

51. Sharma, A.; Kumar, V.; Shahzad, B.; Tanveer, M.; Sidhu, G.P.S.; Handa, N.; Kohli, S.K.; Yadav, P.; Bali, A.S.; Parihar, R.D.; et al. Worldwide Pesticide Usage and Its Impacts on Ecosystem. SN Appl. Sci. 2019, 1, 1446. [CrossRef]

52. Esvelt, K.M.; Smidler, A.L.; Catteruccia, F. Emerging Technology: Concerning RNA-Guided Gene Drives for the Alteration of Wild Populations I ELife. Elife 2014, 3, e03401. [CrossRef]

53. Gantz, V.M.; Jasinskiene, N.; Tatarenkova, O.; Fazekas, A.; Macias, V.M.; Bier, E.; James, A.A. Highly Efficient Cas9-Mediated Gene Drive for Population Modification of the Malaria Vector Mosquito Anopheles Stephensi. Proc. Natl. Acad. Sci. USA. 2015, 112, E6736-E6743. [CrossRef]

54. Dearden, P.K.; Gemmell, N.J.; Mercier, O.R.; Lester, P.J.; Scott, M.J.; Newcomb, R.D.; Buckley, T.R.; Jacobs, J.M.E.; Goldson, S.G.; Penman, D.R. The Potential for the Use of Gene Drives for Pest Control in New Zealand: A Perspective. J. R. Soc. N. Zeal. 2018, 48, 225-244. [CrossRef]

55. Moro, D.; Byrne, M.; Kennedy, M.; Campbell, S.; Tizard, M. Identifying Knowledge Gaps for Gene Drive Research to Control Invasive Animal Species: The next CRISPR Step. Glob. Ecol. Conserv. 2018, 13, e00363. [CrossRef]

56. James, S.P. Conclusions of the Malaria Commission of the League of Nations. Br. Med. J. 1927, 2, 340-344. [CrossRef] [PubMed]

57. WHO. World Malaria Report 2020: 20 Years of Global Progress and Challenges. Available online: https://www.who.int/ publications/i/item/9789240015791 (accessed on 15 March 2021).

58. Teem, J.L.; Ambali, A.; Glover, B.; Ouedraogo, J.; Makinde, D.; Roberts, A. Problem Formulation for Gene Drive Mosquitoes Designed to Reduce Malaria Transmission in Africa: Results from Four Regional Consultations 2016-2018. Malar. J. 2019, 18, 347. [CrossRef]

59. Hammond, A.; Galizi, R.; Kyrou, K.; Simoni, A.; Siniscalchi, C.; Katsanos, D.; Gribble, M.; Baker, D.; Marois, E.; Russell, S.; et al. A CRISPR-Cas9 Gene Drive System Targeting Female Reproduction in the Malaria Mosquito Vector Anopheles Gambiae. Nat. Biotechnol. 2016, 34, 78-83. [CrossRef]

60. Kyrou, K.; Hammond, A.M.; Galizi, R.; Kranjc, N.; Burt, A.; Beaghton, A.K.; Nolan, T.; Crisanti, A. A CRISPR-Cas9 Gene Drive Targeting Doublesex Causes Complete Population Suppression in Caged Anopheles Gambiae Mosquitoes. Nat. Biotechnol. 2018, 36, 1062-1071. [CrossRef] [PubMed]

61. Simoni, A.; Hammond, A.M.; Beaghton, A.K.; Galizi, R.; Taxiarchi, C.; Kyrou, K.; Meacci, D.; Gribble, M.; Morselli, G.; Burt, A.; et al. A Male-Biased Sex-Distorter Gene Drive for the Human Malaria Vector Anopheles Gambiae. Nat. Biotechnol. 2020, 38, 1054-1060. [CrossRef]

62. Pham, T.B.; Phong, C.H.; Bennett, J.B.; Hwang, K.; Jasinskiene, N.; Parker, K.; Stillinger, D.; Marshall, J.M.; Carballar-Lejarazú, R.; James, A.A. Experimental Population Modification of the Malaria Vector Mosquito, Anopheles Stephensi. PLoS Genet. 2019, 15, e1008440. [CrossRef]

63. Carballar-Lejarazú, R.; Ogaugwu, C.; Tushar, T.; Kelsey, A.; Pham, T.B.; Murphy, J.; Schmidt, H.; Lee, Y.; Lanzaro, G.C.; James, A.A. Next-Generation Gene Drive for Population Modification of the Malaria Vector Mosquito, Anopheles Gambiae. Proc. Natl. Acad. Sci. USA 2020, 117, 22805-22814. [CrossRef]

64. OIE. OIE-Listed Diseases 2021: OIE-World Organisation for Animal Health. Available online: https://www.oie.int/en/animalhealth-in-the-world/oie-listed-diseases-2021/ (accessed on 15 March 2021).

65. Vargas-Terán, M.; Hofmann, H.C.; Tweddle, N.E. Impact of Screwworm Eradication Programmes Using the Sterile Insect Technique. In Sterile Insect Technique: Principles and Practice in Area-Wide Integrated Pest Management; Springer Netherlands: Dordrecht, The Netherlands, 2005; pp. 629-650. [CrossRef]

66. Grunwald, H.A.; Gantz, V.M.; Poplawski, G.; Xu, X.R.S.; Bier, E.; Cooper, K.L. Super-Mendelian Inheritance Mediated by CRISPR-Cas9 in the Female Mouse Germline. Nature 2019, 566, 105-109. [CrossRef]

67. GISD. 100 of the World's Worst Invasive Alien Species. Available online: http://www.iucngisd.org/gisd/100_worst.php (accessed on 15 March 2021).

68. McFarlane, G.R.; Whitelaw, C.B.A.; Lillico, S.G. CRISPR-Based Gene Drives for Pest Control. Trends Biotechnol. 2018, 36, 130-133. [CrossRef]

69. Galizi, R.; Hammond, A.; Kyrou, K.; Taxiarchi, C.; Bernardini, F.; O’Loughlin, S.M.; Papathanos, P.A.; Nolan, T.; Windbichler, N.; Crisanti, A. A CRISPR-Cas9 Sex-Ratio Distortion System for Genetic Control. Sci. Rep. 2016, 6. [CrossRef] 
70. Burt, A.; Deredec, A. Self-Limiting Population Genetic Control with Sex-Linked Genome Editors. Proc. R. Soc. B Biol. Sci. 2018, 285. [CrossRef]

71. Prowse, T.A.A.; Cassey, P.; Ross, J.V.; Pfitzner, C.; Wittmann, T.A.; Thomas, P. Dodging Silver Bullets: Good CRISPR Gene-Drive Design Is Critical for Eradicating Exotic Vertebrates. Proc. R. Soc. B Biol. Sci. 2017, 284. [CrossRef] [PubMed]

72. Bishop, T.F.; Van Eenennaam, A.L. Genome Editing Approaches to Augment Livestock Breeding Programs. J. Exp. Biol. 2020, 223 (Suppl. 1). [CrossRef] [PubMed]

73. EU-SAGE. European Sustainable Agriculture through Genome Editing (EU-SAGE). Available online: https://www.eu-sage.eu/ sites/default/files/2020-07/OpenStatementEU-SAGEJuly2020_EN.pdf (accessed on 15 March 2021).

74. Regnault-Roger, C. GMOs and Genome Edited Organisms (GEOs): Regulatory and Geopolitical Challenges; Fondation pour l'innovation Politique (Fondapol): Paris, France, 2021.

75. Regnault-Roger, C. New Genomic Techniques (NGTs): The European Commission Opens the Door. An Historical Challenge for French EU Presidency. Available online: https://www.europeanscientist.com/en/features/new-genomic-techniques-ngts-theeuropean-commission-opens-the-door-an-historical-challenge-for-french-eu-presidency/ (accessed on 21 May 2021). 